and in genetics; this year these subjects are in the capable hands of V. H. Cheldelin and T. E. King, E. R. and T. C. Stadtman, and Wyss and Haas, respectively. The article on metabolism is restricted to a comprehensive and instructive survey of publications dealing with fatty-acid, pyruvate, amino-acid and. steroid metabolism. Shorter articles on specific aspects of microbial metabolism involve a reappraisal of nitrogen fixation and an account of food poisoning. Clinical and biological considerations concerning antibiotics are surveyed by F. R. Heilman, who includes a useful section on the growth and nutritional effects of antibiotics, while their large-scale production is discussed, together with that of many other industrial 'fermentation' products by A. Ledingham. Viruses form the subject of four contributions dealing specifically with developmental stages, biochemical aspects of growth, toxins, and the ecology of mosquito-borne viruses. Most authors have noted the latest date for which they have surveyed the literature, and this varies with different articles from December 1952 to February 1953.

The "Review" also provides surveys of developing fields ; subjects dealt with this year for the first time in the series are 'Amcebiasis', medical mycology, and the metabolism, nutrition and chemotherapy of helminths. The range of modern microbiology is further emphasized by a paper, with 313 references, on the effect of adrenocortical hormones in infection and immunity. To this, F. Haurowitz adds another 252 references dealing with our understanding of the chemical basis of immunological phenomena. A collection of papers such as this is particularly valuable in that it emphasizes experiences in one field which may have repercussions in others; for example, several contributors refer to the effects that the increasing use of wide-spectrum antibiotics brings in its train, not the least of which is an apparent promotion of growth of pathogenic fungi.

One of the most stimulating, though alarming, consequences of reading this "Review" is the realization of the multitudinous unsolved problems in microbiology. H. E. Pearson stresses this feeling, at the end of his contribution on biochemical aspects of viral growth, by the words: "The principal need is to work, work, work". The average microbiologist may well feel that a collection of 3,504 references in a survey of one year of research presents work enough, and it is the existence of "Annual Reviews" such as this which makes it possible for him to direct his reading with optimal economic regard for his own original contributions in the future.

E. F. GALE

\section{HANDBOOK OF THE PLANT ALKALOIDS}

The Alkaloids

Chemistry and Physiology. Edited by R. H. F. Manske and H. L. Holmes. Vol. 2. Pp. viii + 587. (New York: Academic Press, Inc., 1952.) 14.50 dollars.

$\mathrm{T}$

HE editors, contributors and publishers of this second volume on the plant alkaloids are to be warmly congratulated for fully maintaining the excellence of their first volume, which was published in 1950 (see Nature, 167,$48 ; 1951$ ). In the preface to the latter, the editors set out their object- "to assemble in five volumes all the pertinent knowledge of the chemistry and pharmacology of the alkaloids". The reader of the first volume was not clearly informed how this aim in respect of the pharmacology was going to be attained, but in the preface to the second volume the editors announce that they "have been able to secure the cooperation of a number of com. petent pharmacologists to contribute chapters on a variety of physiological and pharmacological responses and these are scheduled to appear in Volume V".

In this second volume, the nine chapters are distributed as follows. The first and second chapters are on the morphine alkaloids (H. L. Holmes and, in part, G. Stork), the third chapter on sinomenine (H. L. Holmes), the fourth on colchicine (J. W. Cook and J. D. Loudon), the fifth on alkaloids of the Amaryllidaceae (J. W. Cook and J. D. Loudon), the sixth on acridine alkaloids (J. R. Price), the seventh on indole alkaloids (L. Marion), the eighth on the erythrina alkaloids (L. Marion), and the last chapter on strychnos alkaloids, Part 2 (H. L. Holmes).

These chapters maintain a remarkably high standard; they are comprehensive, readable and critical. They reveal many unsolved problems and for many a year should be an inspiration to professor and student alike. The constitution of morphine and its congeners has attracted more attention than that of any other alkaloid, and it is thought-arresting, if not provocative, to read that the structure of morphine has been established, except for the location of the ethanamine chain. An up-to-date discussion of the stereochemical arrangement of atoms in morphine and in strychnine is to be found in the appropriate chapters.

In the chapter on colchicine, the authors have dealt exhaustively with its chemistry and have then almost equally exhaustively dealt with the biological effects of this remarkable substance. In doing this they have presented an ideal example of the general aim of the editors discussed earlier; but it would, doubtless, be impracticable to extend this practice to every alkaloid even in a work of five volumes.

In reading through this volume, I was struck by the fact that many of the chapters could have been made more colourful by the freer mention in the text of the many assiduous and talented chemists who have contributed to the solution of what is so far known instead of the reader being confronted by a number, the key to which is found in the list of references at the end of the chapter. The student especially needs the name of the discoverer of any fact, either in the text or in a system of references at the foot of each page. On the system at present adopted the name of the discoverer of the golden nugget may be mentioned in the text, but the producers of the gold dust are hidden away at the end of the chapter.

Although an American publication, the reader would have to search hard to find evidence of such in the text of the chapters. To the British the spelling of "homolog" and "aluminum" are unusual, and the sentence "the hydroxyl group in the former occupies a different position than it does in the latter" is of a form not infrequently found in transAtlantic chemical literature.

The volume is remarkably free from errors. On p. 409 formulæ LXXVI and LXXVII are identical but purport to represent a base and its tetrahydro derivative, while on p. 420 there is a reference number $415 a$ which is not included in the list of references at the end of the chapter.

HAROLD KING 